\title{
Os efeitos da educação financeira no comportamento de consumo: Um estudo com
}

\section{idosos de baixa renda}

\author{
The effects of financial education on consumer behavior: A study with low-income elderly \\ Los efectos de la educación financiera en el comportamiento del consumidor: Un estudio con \\ ancianos de bajos ingresos
}

Recebido: 20/04/2021 | Revisado: 27/04/2021 | Aceito: 29/04/2021 | Publicado: 14/05/2021

\author{
Rafaela Aires Tavares Santos \\ ORCID: https://orcid.org/0000-0002-9396-8162 \\ Universidade de Coimbra, Portugal \\ E-mail: rafaelaaires0122@gmail.com \\ Waldecy Rodrigues \\ ORCID: https://orcid.org/0000-0002-5584-6586 \\ Universidade Federal do Tocantins, Brasil \\ E-mail: waldecy@uft.edu.br \\ Carine de Oliveira Nunes \\ ORCID: https://orcid.org/0000-0003-4659-699X \\ Universidade de Coimbra, Portugal \\ E-mail: carine.nunes@ifto.edu.br
}

\begin{abstract}
Resumo
Contexto: Este trabalho deriva de uma pesquisa participante, desenvolvida através da implementação de um programa de educação financeira para um grupo de idosos com renda de até 2 salários mínimos no município de Palmas - TO. Objetivo: Discutir os efeitos da educação financeira sobre o conhecimento e comportamento financeiros de idosos de baixa renda. Método: Com enfoque qualitativo, a coleta de dados foi realizada através de grupos focais, sendo feita a transcrição e a análise do conteúdo, conforme preconiza Bardin (2011). Resultados: Os resultados mostraram que os idosos que participaram do programa apropriaram-se de novos conhecimentos sobre planejamento e organização financeira; desenvolveram estratégias para organizar o orçamento doméstico buscando a redução do endividamento; utilizaram ferramentas de controle financeiro e poupança para a construção de um hábito mais saudável sobre as finanças pessoais. Conclusão: Práticas de educação financeira podem contribuir com a criação da autonomia e empoderamento do consumidor idoso.
\end{abstract}

Palavras-chave: Educação financeira; Comportamento financeiro; Idosos; Consumo.

\begin{abstract}
Context: This work derives from a participatory research, developed through the implementation of a financial education program for a group of elderly people with an income of up to 2 minimum wages in the city of Palmas TO. Objective: To discuss the effects of financial education on the financial knowledge and behavior of low-income elderly people. Method: With a qualitative approach, data collection was carried out through focus groups, with transcription and content analysis, as recommended by Bardin (2011). Results: The results showed that the elderly who participated in the program acquired new knowledge about planning and financial organization; developed strategies to organize the domestic budget seeking to reduce indebtedness; used financial control and savings tools to build a healthier habit on personal finances. Conclusion: Financial education practices can contribute to the creation of autonomy and empowerment for the elderly consumer.
\end{abstract}

Keywords: Financial education; Financial behavior; Seniors; Consumption.

\section{Resumen}

Contexto: Este trabajo deriva de una investigación participativa, desarrollada a través de la implementación de un programa de educación financiera para un grupo de personas mayores con ingresos de hasta 2 salarios mínimos en la ciudad de Palmas - TO. Objetivo: discutir los efectos de la educación financiera en el conocimiento y el comportamiento financiero de las personas mayores de bajos ingresos. Método: Con un enfoque cualitativo, la recolección de datos se realizó a través de grupos focales, con transcripción y análisis de contenido, según lo recomendado por Bardin (2011). Resultados: Los resultados mostraron que los adultos mayores que participaron del programa adquirieron nuevos conocimientos sobre planificación y organización financiera; desarrolló estrategias para organizar el presupuesto interno buscando reducir el endeudamiento; utilizó herramientas de ahorro y control financiero para desarrollar un hábito más saludable en las finanzas personales. Conclusión: Las prácticas de educación financiera pueden contribuir a la creación de autonomía y empoderamiento del consumidor mayor.

Palabras clave: Educación financiera; Comportamiento financiero; Ancianos; Consumo. 


\section{Introdução}

A melhoria na renda dos idosos veio acompanhada de mudanças importantes no cotidiano, a absorção de novos valores e o despertar de novas necessidades, influenciados pelas transformações sociais e pelo avanço tecnológico e novas responsabilidades no lar, são exemplos. Com isso, os idosos de baixa renda tem sido vistos no Brasil como novos consumidores (Marino \& Sampaio, 2013; Buas, 2015, Goyal \& Kumar, 2021).

Ante isso, o mercado de bens e serviços não desacelera o seu investimento neste público, a cada dia são formados contextos de "consumo facilitado" por meio de parcelamentos, crediários próprios, cartões de crédito, e pela oferta de crédito consignado (Buas, 2015). Esse contexto de investidas mercadológicas é também um cenário muito propício para o crescimento do endividamento e da inadimplência dessa parcela da população, principalmente porque suas condições sociais e econômicas os classificam como consumidores potencialmente mais vulneráveis (Buas, 2015). Neste sentido, a utilização de estratégias que contribuam com a mudança deste cenário é urgente e de grande importância.

Uma ferramenta que tem ganhado espaço e apresentado resultados robustos na educação para redução do endividamento e inadimplência das famílias que se encontram em situação de vulnerabilidade é a educação financeira, programas e ações de órgãos como a Organização para a Cooperação e Desenvolvimento Econômico - OCDE em parceria com o Banco Mundial, Fundo Monetário Internacional e Bancos Centrais deram início a uma expansão do tema por vários países no mundo. Os primeiros a aderir foram os Estados Unidos e o Reino Unido, e atualmente mais de 50 países, incluindo o Brasil, têm implementado ações e estratégias para desenvolvimento de programas a nível nacional levando o tema para as escolas, universidades e comunidade em geral (Organização para a Cooperação e Desenvolvimento Econômico, 2020).

No Brasil, desde 2010, têm-se desenvolvido ações e programas de educação financeira coordenados pela Estratégia Nacional de Educação Financeira do Brasil - ENEF, juntamente com a Associação de Educação Financeira do Brasil - AEFBRASIL. A proposta da ENEF e da AEF Brasil é que este projeto venha se tornar uma política pública de amplo alcance, para melhorar a realidade dos adultos economicamente vulneráveis do país. Para alcançar esse propósito, a AEF-BRASIL firma parcerias com instituições em todo território nacional a fim de formar multiplicadores do programa (Banco Central do Brasil [BACEN], 2011).

Nesta direção, a Universidade Federal do Tocantins - UFT, tornou-se uma parceira da AEF-BRASIL, por meio do Programa de Pós Graduação em Desenvolvimento Regional - PPGDR, e propôs-se a executar o Programa de Educação Financeira "Eu e minha aposentadoria, organizando a vida financeira", que tem como público alvo idosos de baixa renda.

O programa foi executado, como parte desta pesquisa, com os idosos alunos da Universidade da Maturidade UMA/UFT - campus Palmas e também com idosos cadastrados em dois Centros de Referência de Assistência Social - CRAS do município de Palmas, no período de fevereiro a abril de 2018. Além da oferta do programa, esta pesquisa propôs-se, majoritariamente, a discutir os efeitos do programa sobre o conhecimento e o comportamento financeiro dos idosos participantes.

Para alcançar o objetivo supracitado, este artigo está organizado de forma a, após introduzir a temática, apresentar definições sobre o perfil do consumidor idoso e sobre possíveis estratégias para educação financeira. Na sequência, a seção metodológica estabelece as escolhas das abordagens utilizadas na presente pesquisa, tratando especificamente da pesquisa participante, do grupo focal e da análise de conteúdo. A seção posterior traz a apresentação dos resultados da aplicação metodológica. Finalmente, as discussões, conclusões e direcionamentos do estudo são apresentados.

\section{O Idoso de Baixa Renda, um Consumidor Vulnerável}

A partir da década de 70, o Brasil iniciou um processo de transição demográfica que transformaria a estrutura social do país; de famílias numerosas com muitos filhos, que viviam majoritariamente em zona rural, a sociedade começa a se tornar 
principalmente urbana, com menos e filhos e um contingente cada vez maior de pessoas com 60 anos ou mais (Miranda, Mendes, Da Silva, 2016).

Esse crescente aumento da população idosa veio acompanhado de inúmeras alterações sociais, uma delas foi na própria organização familiar, no que diz respeito ao papel e/ou participação do idoso. Até a década de 90, o idoso era visto como um dependente dos recursos e cuidados da família, em muitos casos sem renda alguma, era tido como a parcela pobre e sem autonomia na sociedade (Caldas, 2003).

Este cenário mudou com o advento das aposentadorias e pensões, que deu ao idoso uma nova expressão para com a família e a sociedade. Assim, aquele que antes era dependente, agora, em muitos lares brasileiros, passa a ser o provedor e integrante da parcela consumidora ativa do país, com acesso a bens e serviços pensados para sua faixa etária e ainda com acesso a crédito no mercado financeiro (Buas, 2015).

Esse novo panorama coloca o idoso em evidência, tornando-o alvo do mercado de bens, serviços e financeiro, que teve o interesse despertado para novos negócios visando esse novo público consumidor. Essas investidas partem desde a facilidade de fazer compras parceladas em crediários, cartões de créditos e cartões de lojas até as ações bancárias para a venda de empréstimos consignados que têm como alvo constante o idoso aposentado (Doll, Ramos, Buaes, 2015; Fundo de População das Nações Unidas [UNFPA], 2012). Por outro lado, esse idoso não tem acesso a um suporte social para ajudar-lhe a lidar com as investidas e até abusos do mercado, expondo -o assim, a um cenário de vulnerabilidade.

Um reflexo disso pode ser percebido pelo crescente número de endividamento da pessoa idosa no Brasil, dados apontam um aumento de 45\% no número de idosos endividados no Brasil, para o período de abril de 2018 a abril de 2019 (BACEN, 2019). Além do endividamento, a inadimplência torna-se um outro fator de impacto na vida do idoso. Sobre essa questão, os dados do (Serviço de Proteção ao Crédito [SPC], 2019) mostram que a inadimplência entre os consumidores dessa fase é uma das que mais crescem no país, e as despesas mais afetadas são as despesas com água, luz e moradia, o que afeta diretamente a qualidade de vida desse idoso, divulgou ainda que de cada 10 inadimplentes no país, 3 são idosos.

Essa situação remete à reflexão de que a inserção do idoso de baixa renda em um cenário consumidor não veio acompanhada de uma rede de apoio que o preparasse para lidar com todas essas transformações. Dessa forma, destaca-se a importância de intervenções educativas para essa parcela da população, que é potencialmente mais vulnerável, considerando sua idade, baixa escolaridade e sua classe social (Buas, 2015).

\section{A Estratégia da Educação Financeira na Educação dos Consumidores}

A partir do século XX, diversos países despertaram-se para a necessidade de educar consumidores, alguns fatores como os desafios econômicos, as fortes evidências de baixos níveis de alfabetização financeira e seus efeitos adversos sobre indivíduos e famílias, como o endividamento e a inadimplência, as mudanças tecnológicas, a globalização e mudanças regulatórias e institucionais, são motores desta nova perspectiva (Goyal \& Kumar, 2021).

Em termos conceituais, a educação financeira pode ser compreendida como a habilidade dos indivíduos em fazer escolhas adequadas ao administrar suas finanças pessoais durante a vida (Pinheiro, 2008). A definição de educação financeira dada pela Organização para Cooperação e Desenvolvimento Econômico - OCDE (2005) é uma das mais reconhecidas e utilizadas na literatura: "O processo pelo qual os consumidores/investidores financeiros melhoram sua compreensão dos produtos financeiros, conceitos e riscos e, por meio de informações, instruções e/ou conselhos objetivos, desenvolvem habilidades e confiança para se tornar mais consciente dos riscos e oportunidades financeiros".

$\mathrm{O}$ processo da educação financeira deve ser realizado de forma justa e imparcial, de forma a promover o desenvolvimento das competências individuais sempre atentando para as características de cada local de maneira a adequar-se à realidade dos participantes. O resultado desse processo é a alfabetização financeira que se trata de "uma combinação de 
consciência financeira, conhecimento, habilidades, atitudes e comportamentos necessários para tomar decisões financeiras sólidas e, em última análise, alcançar o bem-estar financeiro" (OCDE, 2013, p. 82).

Além disso, alfabetização financeira não deve ser algo rebuscado ou difícil, o ideal é que se comece devagar, com noções básicas, por exemplo: as características e o uso de produtos financeiros, desmitificando o conceito de dívida, progredindo para os mais avançados, que lidam com o conhecimento de conceitos financeiros, o desenvolvimento de habilidades e atitudes para o gerenciamento das finanças pessoais. Dessa forma, é possível atingir as mudanças comportamentais positivas (OCDE, 2005; Garcia, Grifoni, López, \& Mejía, 2013).

As mudanças promovidas pela educação financeira trazem inúmeros benefícios aos indivíduos e à sociedade como um todo. Por meio desse processo, é possível capacitar os indivíduos e permitir que eles gerenciem melhor as finanças e os recursos pessoais e domésticos. É ainda um processo democrático, que se aplica tanto às classes médias emergentes quanto às consolidadoras (Garcia et al., 2013).

A educação financeira tem o poder de promover competências de tomada de decisão segura e pensada, oferece à comunidade fonte de informação que permite a defesa dos seus direitos como consumidores, além de elevar a capacidade de compreender políticas econômicas e sociais adotadas em sua própria economia (Garcia et al., 2013). Visto isso, na última década, a educação financeira foi destaque como alvo de políticas públicas em diversos países, de forma que os formuladores de políticas têm entendido a relevância da educação financeira e vêm adotando-a como um antídoto necessário para a crescente complexidade das decisões financeiras dos consumidores (OCDE, 2005).

Em um período inicial, as pesquisas e ações sobre educação financeira estiveram concentradas majoritariamente nos Estados Unidos e no Reino Unido, tendo como principal foco o ensino médio e universitário, atualmente mais de 50 países, entre eles o Brasil, já tem estratégias de educação financeira implantadas e ativas, para jovens, adolescentes, idosos e mulheres em situação de vulnerabilidade (Fernandes, Lynch e Netemeyer, 2014; Savoia, Saito e Santana, 2007).

\section{Metodologia}

Como estratégia educativa e de empoderamento dos sujeitos, a estudo apoiou-se nos princípios da pesquisa participante, ou seja, na construção de conhecimentos para posterior transmissão aos indivíduos envolvidos com os fenômenos ou fatos observados, visando mudança do quadro observado (Haguette, 2013). O enfoque da pesquisa é qualitativo, nesse tipo de abordagem são exploradas, particularmente, as técnicas de observação e coleta de dados primários (Richardson, 2007).

Já a coleta de dados foi realizada através de grupos focais, essa técnica tem destaque na pesquisa qualitativa porque propicia riqueza de detalhes e flexibilidade na coleta de dados, normalmente não disponíveis quando se aplica uma entrevista individualmente, além disso, há o ganho em espontaneidade pela interação entre os participantes (Oliveira, Leite, Rodrigues, 2007). O trabalho foi desenvolvido com idosos de baixa renda no município de Palmas - TO.Procurou-se analisar os efeitos da educação financeira sobre conhecimento e o comportamento financeiro de idosos de baixa renda, por meio da observação de aspectos como a relação dos idosos com a hábito de poupar dinheiro, o conhecimento sobre dívidas, o comportamento no momento da tomada de decisão financeira e percepção do papel do dinheiro para sua qualidade de vida.

Os participantes tinham idade entre 60 a 85 anos, de 4 a 11 anos de escolaridade, e renda mensal de até dois salários mínimos, a renda é procedente de aposentadorias, pensões, benefícios sociais, trabalhos domésticos, vendas de produtos, trabalho esporádico, entre outros. Os idosos que participaram da pesquisa estavam matriculados e frequentes no projeto da Universidade da Maturidade - UMA da Universidade Federal do Tocantins, Campus Palmas - TO e no programa de convivência do Centro de Referência de Assistência Social - CRAS, de Taquaruçu e da quadra 407 Norte.

A pesquisa foi dividida em duas etapas, a primeira envolve a oferta do programa de educação financeira para os idosos e o primeiro grupo focal, já a segunda etapa configura-se no reencontro dos participantes e o segundo grupo focal, 6 
meses após a intervenção, para levantar a perspectiva dos mesmos sobre a participação no programa e os possíveis efeitos do programa.

O programa de educação financeira - "Eu e minha aposentadoria - Organizando a vida financeira", foi desenvolvido pela AEF-BRASIL como parte das ações que buscam popularizar a educação financeira no Brasil, está estruturado em formato de oficinas temáticas, nas quais, de forma participativa, os idosos constroem conhecimentos sobre planejamento e organização financeira, dívidas, controle financeiro, empréstimos, planejamento futuro, entre outros temas recomendado.

No total foram realizadas 4 oficinas com cada grupo (UMA, CRAS Taquaruçu e CRAS 407 Norte) sendo que cada oficina tinha uma duração de 4 horas, e foram realizadas em 4 encontros locais e mais um encontro geral de encerramento, totalizando 5 encontros. Cada oficina ministrada contou com um instrutor mediador responsável pelo desenvolvimento das atividades e acadêmicos que realizavam a monitoria. Nas oficinas, as estratégias de aprendizagem utilizadas deram lugar à interação, o debate, a participação e o compartilhamento das experiências de consumo vividas pelos idosos.

Após 6 meses da realização das oficinas foi realizado um reencontro com os grupos com o objetivo de conhecer os efeitos da intervenção. Foram investigadas situações cotidianas nas quais as participantes utilizaram os conhecimentos construídos no curso. Em seguida a coleta de dados, foi realizada a transcrição das falas e a análise do conteúdo, conforme preconizou Bardin (2011), as etapas para realização da análise de conteúdo são, respectivamente, a pré-análise (contato inicial com os documentos, leitura, elaboração de indicadores para interpretação); a exploração do material (codificação dos dados e classificação em categorias de análise); o tratamento dos resultados (compreende a inferência e interpretação a partir dos objetivos da pesquisa).

Consideradas as palavras e o contexto em que foram inseridas, a consistência dos argumentos, a frequência e a extensão dos comentários, as falas foram organizadas dentro das categorias de análise pré-definidas, que correspondem aos temas abordados em cada encontro (I- Fonte de Renda e Despesa - "De onde o meu dinheiro vem e para onde o meu dinheiro vai"; II- Dívidas - "Dívidas na ponta do lápis", III- Gastos domésticos - "Economia Doméstica”, IV- Importância do planejamento financeiro- "Planejando os próximos Passos").

Os participantes que expuseram suas opiniões foram codificados com os numerais de 1 a 10. Ademais, a transcrição foi submetida a uma cuidadosa leitura onde procurou-se identificar, na fala dos participantes, atitudes diferentes, mudanças de comportamentos e práticas sobre a vida financeira.

\section{Resultados e Discussão}

\section{$5.1 \mathrm{O}$ reconhecimento das fontes de renda e de gastos, as dívidas, o orçamento doméstico e os planos para uma vida} financeira mais equilibrada

A primeira oficina realizada com os idosos foi a oficina temática "De onde o meu dinheiro vem e para onde o meu dinheiro vai”. O principal objetivo deste encontro foi proporcionar aos idosos maior clareza sobre seus ganhos e seus gastos, ou seja, levá-los a identificar as fontes de renda que possuem e o quanto têm de entrada financeira todos os meses. Da mesma forma, neste encontro, os idosos foram levados a identificar com o que gastam o seu dinheiro e quais as principais fontes de despesas. Além de estimular os idosos a refletir sobre como estão gastando o seu dinheiro, neste encontro foi possível também ajudá-los a diagnosticar como estava a atual situação financeira deles, isto é, se o que ganham tem sido suficiente para todas as despesas do mês ou se é insuficiente.

Já na primeira oficina, ao abordar o tema, foi possível ouvir alguns relatos, como a fala de um dos participantes que afirmou não ter controle de como tem gasto o dinheiro:

Participante 1: "Não tenho a menor ideia de para onde vai o meu dinheiro, eu recebo a minha aposentadoria e ainda não éo 
fim do mês e já não tenho nada”. Outros relataram que usam o dinheiro praticamente todo para as despesas básicas:

Participante 2: "O meu dinheiro vai todo para pagar água, luz, gás, alimentação e remédio, o problema é que se eu preciso comprar alguma coisa no fim do mês não tenho mais nada".

A oficina 2 trabalhou o assunto das dívidas, o tema era: "Dívidas na ponta do lápis". Neste encontro, o objetivo foi ampliar o conhecimento do idoso sobre tipos de dívidas e contribuir no reconhecimento de estar ou não endividado. Para isso, foi trabalhado com eles o conceito de dívida e ainda os elementos e riscos que estão presentes nas dívidas, como parcelas, juros, inadimplência entre outros. De posse do conhecimento teórico os idosos foram estimulados a realizarem o levantamento de suas próprias dívidas.

Nesta atividade, foi observado que muitos dos idosos entendem como dívidas apenas os compromissos que fizeram e não conseguiram cumprir. Isso foi observado, principalmente com falas como:

Participante 1: "Eu não tenho dividas, eu compro parcelado, mas pago tudo em dia", Participante 3: "Não devo nada, tenho minhas parcelas nas lojas e meu empréstimo, mas pago até antecipado, antes do vencimento".

Participante 6: "é, se tá pagando direitinho não tem problema, não pode é ter o nome sujo".

Diante desses discursos, já foi desmistificado o conceito de dívida e esclarecido que todo compromisso assumido, estando ele em atraso ou não, é um tipo de dívida. Um momento muito importante desta oficina foi quando os idosos começaram a descrever os compromissos que tinham e que pagavam mensalmente. Para muitos, foi a primeira vez que visualizaram as suas "dívidas na ponta do lápis". Falas como:

Participante 8: "Nossa professora, essas parcelinhas que fazemos aqui e ali, no final levam todo nosso dinheiro", foram ouvidas.

Além do conhecimento sobre as dívidas, nesta oficina, os idosos foram estimulados a "Parar e Pensar" antes de tomar uma decisão financeira. Durante a discussão sobre esse tema, alguns idosos revelaram que, muitas vezes, faziam compras sem pensar se estava mesmo precisando. Nesse sentido, uma das participantes relatou:

Participante 4: "Eu não penso mesmo não, professora. Várias vezes, entro na loja e saio de lá com 3 ou 4 peças e, muitas vezes, nem são para mim, são para os outros". Outros relataram que o fato de ter netos os impulsionam a comprar, mesmo sem ter o dinheiro na hora:

Participante 7: "Vejo o brinquedo ou a roupinha para meu netinho, já quero comprar logo".

Sobre essa questão, foi trabalhado com eles a importância de analisar a situação financeira antes de fazer qualquer compra, verificar se o item que será comprado é importante naquele momento ou se pode esperar, e ainda, dar preferência para as compras à vista no lugar das parcelas.

Na sequência às oficinas ministradas, a oficina 3 trouxe a temática da economia doméstica. Neste encontro, os idosos foram, inicialmente, estimulados a identificar qual a principal fonte de despesa doméstica de sua família. Assim, de forma 
lúdica e interativa, os idosos foram apresentando o que consideram o maior gasto doméstico. Após esse diagnóstico os idosos foram conduzidos à busca de estratégias que contribuíssem para a redução desses gastos, de forma que, ao fim da oficina foi possível observar as falas deles sobre o assunto:

Participante 8: "Essa dica de fazer o sabão caseiro é muito boa, vou aproveitar na minha casa e vou plantar uma hortinha no meu quintal e ainda posso vender o cheiro verde e fazer um dinheiro extra".

Nesta oficina, os idosos também foram orientados em como economizar no momento das compras no supermercado, na preparação dos alimentos com dicas de reaproveitamento e aproveitamento da comida que se prepara no dia a dia visando eliminar o desperdício.

A última oficina realizada abordou o tema "Planejamento futuro". Neste encontro, os idosos foram estimulados a identificar e a planejar caminhos para melhorar sua situação financeira atual. Nesta oficina, os principais temas abordados foram planejamento de fontes de rendas extra, poupança, estratégias para redução de gastos e aprender a dizer não.

Com a discussão desses temas, os idosos tiveram um tempo para refletir um pouco mais sobre o comportamento relacionado a suas finanças. Uma das participantes relatou que, durante o processo do curso, ela percebeu que a venda de produtos que ela fazia não estava sendo lucrativa:

Participante 5: "Durante as aulas, percebi que precisava melhorar a forma de gerenciar o meu dinheiro, até tenho uma fonte de renda extra, que é a venda de produtos de beleza, porém eu vi que, como não me organizava, ela não estava sendo lucrativa".

Ademais, trabalhar o tema aprender a dizer não foi de grande importância, pois muitos idosos assumem a responsabilidade dos netos e filhos e, por muitas vezes, endividam-se para ajudá-los. Logo, tal tema foi discutido levando o idoso a compreender que a ajuda aos filhos ou aos netos, ou mesmo a compra de presentes, não é algo errado; no entanto, é necessário, primeiramente, analisar se há condições suficientes para fornecer ajuda ou comprar um presente.

As oficinas não foram apenas um momento em que os idosos recebiam conteúdos sobre educação financeira, os encontros foram conduzidos de uma forma participativa a fim de propiciar momentos e espaço em que os idosos pudessem partilhar suas experiências com o consumo e sobre a relação deles com o dinheiro. Esses momentos de partilha foram desenvolvidos por meio do diálogo, dinâmicas, rodas de conversa e atividades práticas, sendo essenciais para que a condução das oficinas fosse ao encontro da realidade dos idosos.

\subsection{0 reencontro}

No decorrer das oficinas os idosos tiveram a oportunidade de, longe da rotina diária, analisarem a situação da sua vida financeira, puderam falar abertamente, debater, questionar e pensar soluções para melhoria da qualidade de vida. Como exposto, durante os encontros foi permitido a discussão sobre orçamento, dívidas, ganhos, atitudes que podem melhorar o dia a dia, poupança, planejamento entre outros.

No reencontro voltou-se a estes temas, com o objetivo de saber se a participação em um programa de educação financeira foi contributiva para melhoria da perspectiva e ação dos idosos sobre a vida financeira. As intervenções tiveram início tomando por base os assuntos das oficinas.

Durante as oficinas, cada um dos participantes recebeu uma cartilha e fichas onde podiam fazer o registro das despesas do mês, a análise destes registros mostraram que mais de $50 \%$ do orçamento mensal dos idosos é destinado às 
despesas básicas (alimentação, água, luz, gás, medicamentos, moradia), logo, é de grande importância que eles se apropriem de ferramentas e conhecimentos que contribuem para a melhor gestão do seu orçamento, que, no caso específico de idosos de baixa renda, não tem muita folga. Alguns diálogos sobre o tema ilustram novos posicionamentos e a apropriação de estratégias de melhor gerenciamento dos recursos:

Participante 2: "Antes eu não pensava em mim, só pensava nos outros, agora não, moro com meu filho, então as despesas passaram a ser divididas, eu pago água e ele paga a luz, o supermercado é dividido entre eu e ele, a internet, ele que paga, porque usa mais, eu aprendi isso aqui, porque antes eu pagava tudo, agora não."

Participante 9: "Durante o curso, eu percebi que tinha uma mania de comer sempre que ia na rua, e era um dinheiro que gastava que somando no fim do mês fazia falta, então eu parei com isso, como em casa, porque, como melhor e gasto menos."

Participante 8: "Já segui a dica de ter uma hortinha em casa e de fazer o sabão caseiro, já economizo, a próxima dica a seguir será a de dividir o combustível com o vizinho no momento de ir fazer as compras no supermercado”.

Participante 9: "Antes do curso, eu ia muito ao mercadinho da minha quadra, comprava as coisas lá, depois percebi o quanto lá era mais caro, agora vou ao supermercado maior que tem preços melhores, assim o dinheiro rende mais”.

Participante 6: "O curso me ajudou muito, uma coisa que faço agora é anotar o que eu preciso comprar, porque antes eu ia fazer as compras e lembrava tudo, agora não, já esqueço e acabo comprando o que não preciso, e anotando fica bom, porque não compra coisas a mais".

A temática sobre poupança também foi desenvolvida com os idosos durante as oficinas, ressalta-se que, ao trabalhar o tema poupança, não lhes foi apresentados formas de investimentos financeiros, como ações, títulos públicos, letras de crédito, etc., o objetivo foi iniciar por um caminho mais simples, que foi o ato de organizar as finanças pessoais para que ao fim do mês possa sobrar algum dinheiro e ajudá-los a entender que este dinheiro poderia ser guardado para uma eventualidade ou mesmo para aquisição de algo importante, pois, muitos idosos relataram que não conseguiam guardar dinheiro, sempre que tinha algum valor a mais o primeiro impulso era gastar. Em um dos depoimentos dos participantes pode-se perceber:

Participante 10: "eu não podia ter dinheiro na mão, que o primeiro impulso era comprar, porque dinheiro para mim era para gastar, guardar para quê?”.

Este foi um comportamento bastante comum entre os idosos, um dos fatores que pode explicar esse tipo de posicionamento passa pelo contexto histórico da economia brasileira, pois a maiorias destes idosos viveram o período onde a inflação estava descontrolada e suas famílias precisavam comprar e estocar, pois não sabiam como seria no dia seguinte, isso aliado ao momento que as poupanças foram bloqueadas pode explicar, em parte, a ansiedade pelo gastar e também a pouca disposição ou confiança para guardar dinheiro.

Para ajudá-los e incentivá-los a fazer o exercício de poupar foi confeccionado um cofrinho personalizado para os idosos levarem para casa, a fim de terem materializado o tema que foi abordado em sala de aula, na intervenção final foi possível levantar alguns depoimentos dos idosos sobre o efeito do programa neste tema: 
Participante 10: "no curso eu aprendi a poupar, porque, eu não poupava, gastava meu dinheiro com besteira, ia à rua e todo trocado que eu tinha comprava um doce, um biscoito, e eu não posso, porque sou diabético, agora não, coloco no cofrinho, não gasto com doce, não alimento minha diabete e alimento meu cofrinho".

Participante 7: "esse curso me ajudou muito, porque eu gastava meu dinheiro comprando muito presente para meus netos, às vezes desnecessário, recebia o pagamento, ia às lojas na JK e comprava sem pensar, agora não, eu paro, penso e depois vejo se compro ou não, e não gasto tudo de uma vez, só o necessário".

O hábito de poupar não é comum entre os brasileiros, em pesquisa do Serviço de Proteção ao Crédito (2018) foi apurado que apenas $20 \%$ dos Brasileiros, têm algum tipo de poupança, fatores como a conjuntura econômica e o controle financeiro são apontados como os principais entraves para esse cenário. Para o brasileiro de baixa renda, é ainda mais difícil a ideia de poupar, uma vez que, de acordo com a pesquisa, é difícil estabelecer um valor fixo para investimento mensal. E em relação à construção deste hábito, é um processo que leva tempo e exige esforço pessoal.

A temática sobre endividamento, abordada nas oficinas, tem relação direta com o conhecimento financeiro dos idosos. Sob esse ângulo, um comportamento comum entre eles era a afirmação de que dívidas são apenas os compromissos que foram firmados e estão em atraso, ideia esta que foi sendo desmistificada durante os encontros.

A abordagem desse assunto auxilia o idoso em uma mudança de atitude frente às situações que o levam a tomar uma decisão financeira, porquanto compreender o que são dívidas contribui para que o olhar sobre a sua condição financeira seja modificado, de forma que ele passe a, antes de assumir um compromisso, analisar o estado de sua vida financeira com o fito de verificar se ele cabe ou não no seu orçamento.

A proposta do programa em ajudar o idoso a compreender o endividamento é importante ainda por auxiliá-lo a buscar uma melhor relação com o que lhe é oferecido pelo mercado de bens e serviços. Em uma das falas de uma participante no reencontro, podemos observar esse reflexo do curso:

Participante 8: "Eu queria muito comprar um fogão novo, já tinha um pouco de dinheiro, ia comprar parcelado, mas parei e pensei um pouco e vi que podia esperar. Então, no mês seguinte, meu marido me deu o restante do dinheiro e comprei o fogão à vista. Foi bem melhor porque não fiquei devendo.

Participante 5: Um dia destes eu pesquisei, eи queria comprar uma tal coisa, queria comprar a prestação, mas quando fiz a conta, vi que ia ficar muito, muito mais caro, o que que eu fiz? Paguei na hora, comprei, não "tô" devendo e tá tudo tranquilo.

Além dos bens triviais que são oferecidos pela mídia, o idoso tem que lidar ainda com a oferta de crédito que é feita pelas instituições financeiras a todo o momento. Grande parte dessas ofertas é feita sem muitos esclarecimentos para o idoso, induzindo-o a assumir um compromisso financeiro em longo prazo e por um custo muito alto. Uma das principais ofertas é a do crédito consignado, oferecido principalmente para a parcela de idosos aposentados, o que chega a comprometer em média $30 \%$ da renda mensal do aposentado, durante os encontros, os idosos foram orientados a analisar muito bem todas as opções antes de tomar um empréstimo consignado, foi alertado sobre como analisar os valores das parcelas, a questionar os juros, a somar todas as parcelas para saber exatamente o valor que será pago no final.

Participante 2: "o que tem de gente que liga pra oferecer empréstimo, é quase todo dia e eles só falam que a parcela é pequena, com a aposentadoria dá para pagar". 
Participante 1: "é, ninguém fala desses juros não, e a gente nem tem a esperteza de somar as parcelas mesmo não.

Participante 5: é, mas agora já “tamo” espertos.

Para fixar este conhecimento, os idosos realizaram uma atividade de simulação de empréstimos onde puderam analisar e diferenciar vários cenários de taxas de juros, número de parcelas e o que é importante estar atento caso tenha necessidade de fazer um empréstimo.

\section{Considerações Finais}

O objetivo deste trabalho foi analisar os efeitos da educação financeira sobre o conhecimento e o comportamento financeiro de idosos de baixa renda, por meio da análise de conteúdo das narrativas dos participantes do programa "Eu e minha aposentadoria, organizando a vida financeira", foi possível observar o efeito positivo do desenvolvimento de conhecimento sobre educação financeira no cotidiano desse grupo.

Esse efeito positivo foi observado no reencontro, quando as falas dos participantes apontam que os idosos que participaram das oficinas de educação financeira apropriaram-se de novos conhecimentos, desenvolvem práticas de planejamento, como: guardar dinheiro para comprar um bem à vista, ao invés de comprar parcelado; dividir as despesas básicas com aqueles que moram na mesma casa, não assumindo toda a responsabilidade sozinhos; utilizar dos princípio da economia doméstica para otimizar o orçamento; analisar as despesas fixas antes de assumir outro compromisso ou mesmo antes de comprar um presente para alguém; fazer lista de compras no momento de ir ao supermercado; utilizar um cofrinho como incentivo à poupança e pesquisar preços ou de juros antes da tomada de uma decisão financeira.

Os resultados apontados nesta pesquisa corroboram com os percebidos nos trabalhos de Buas (2015) e no relatório de avaliação de impacto da (AEF-BRASIL, 2017) para o projeto piloto do programa aplicado em alguns municípios do Brasil. Esses resultados, incluindo os que foram auferidos neste trabalho, apontam que as práticas de educação financeira podem contribuir com a criação da autonomia e empoderamento do consumidor idoso, pois, além de oportunizar acesso às informações sobre os produtos financeiros, esse tipo de intervenção leva o indivíduo a uma leitura mais crítica sobre o seu comportamento financeiro diante das mais diversas situações cotidianas. Assim esta pesquisa contribuiu de forma significativa para a construção de uma perspectiva nova sobre a vida financeira para os indivíduos participantes.

Outra contribuição desta pesquisa é relacionada à abertura de novos olhares para intervenções e análises dentro da temática aqui estudada, pois, considerando as estimativas para o envelhecimento da população brasileira, o acesso à educação financeira para adultos torna-se um contributo importante para que esse processo ocorra de forma saudável. Como sugestão para pesquisas futuras, propõe-se a expansão desta intervenção para outras regiões do município de Palmas, como também para outros municípios brasileiros, aumentando assim, a amplitude da análise de dados.

\section{Referências}

Associação Brasileira de Educação Financeira - AEF BRASIL. (2017). Relatório de Avalição de programas sociais. http://www.vidaedinheiro.gov.br.

Banco Central do Brasil. (2011). Brasil: implementando a estratégia nacional de educação financeira. http://www.bcb.gov.br/pre/pef/port/Estrategia_ Nacional_Educacao_Financeira_ENEF.pdf .

Buaes, C. S. (2015). Educação financeira com idosos em um contexto popular. Educação \& Realidade, 40(1), 105-127.

Caldas, C. P. (2003). Envelhecimento com dependência: responsabilidades e demandas da família. Cadernos de Saúde Pública, 19, 733-781. 
Research, Society and Development, v. 10, n. 5, e47710515269, 2021

(CC BY 4.0) | ISSN 2525-3409 | DOI: http://dx.doi.org/10.33448/rsd-v10i5.15269

Decreto 7397 de 22 de Dezembro de 2010. (2010). Institui a Estratégia Nacional de Educação Financeira - ENEF, dispõe sobre a sua gestão e dá outras providências.

Doll, J., Ramos, A. C., \& Buaes, C. S. (2015). Apresentação-Educação e Envelhecimento. Educação \& Realidade, 40(1), 9-15.

Fernandes, D., Lynch Jr, J. G., \& Netemeyer, R. G. (2014). Financial literacy, financial education, and downstream financial behaviors. Management Science, 60(8), 1861-1883.

Fundo de População das Nações Unidas [UNFPA]. (2012). Por escolha, não por acaso: Planejamento Familiar, Direitos Humano e Desenvolvimento. http://www.unfpa.org.br/Arquivos/swop2012.pdf.

Garcia, N., Grifoni, A., López, J. C., \& Mejía, D. (2013). Financial education in Latin America and the Caribbean: Rationale, overview and way forward.

Goyal, K., \& Kumar, S. (2021). Financial literacy: A systematic review and bibliometric analysis. International Journal of Consumer Studies, 45(1), 80-105.

Haguette, T. M. F. (2013). Metodologias qualitativas na sociologia. In Metodologias qualitativas na sociologia (pp. 223-p).

Marino, M. R. G. B., \& SAMPAIO, C. A. (2013). Brasil idoso: desafios para o consumo. Ident Cient, 4(1), 22-40.

Miranda, G. M. D., Mendes, A. D. C. G., \& Da Silva, A. L. A. (2016). O envelhecimento populacional brasileiro: desafios e consequências sociais atuais e futuras. Revista brasileira de geriatria e gerontologia, 19(3), 507-519.

Oliveira, A. A. R. D., Leite, C. A. P., \& Rodrigues, C. M. C. (2007). O Processo de construção dos grupos focais na pesquisa qualitativa e suas exigências metodológicas. Rio de Janeiro.

Organisation for Economic Co-Operation and Development. OCDE. (2013). Financial literacy and inclusion: Results of OECD/INFE survey across countries and by gender. OECD Centre, Paris, France.

Organisation for Economic Co-Operation and Development. OCDE. (2005). OECD's Financial Education Project. OECD Centre, Paris, France.

Organisation for Economic Co-Operation and Development. OCDE. (2020). OECD's Recommendation on Principles and Good Practices for Financial Education and Awareness. OECD Centre, Paris, France.

Pinheiro, R. P. (2008). Educação financeira e previdenciária, a nova fronteira dos fundos de pensão. Peixoto Neto.

Richardson, R. J. (2007). Pesquisa social: métodos e técnicas. Atlas.

Savoia, J. R. F., Saito, A. T., \& Santana, F. D. A. (2007). Paradigmas da educação financeira no Brasil. Revista de Administração pública, 41(6), $1121-1141$. 